\title{
EL FUTURO DE LA UNIVERSIDAD ESPAÑOLA Y DE LA LEY QUE LA REGULA
}

\section{THE FUTURE OF SPANISH UNIVERSITY AND THE LAW THAT REGULATES IT}

José M. Delgado García: Universidad Pablo de Olavide de Sevilla (España). jmdelgar@dex.upo.es

\section{CURRÍCULUM VITAE}

Licenciado en Medicina y Cirugía en la Facultad de Medicina de la Universidad de Sevilla (España), de la cual es Doctor con premio extraordinario en 1972. Completó su formación con estudios de Psiquiatría en las Universidades de Barcelona y Sevilla (España).

\section{RESUMEN}

La Universidad presente y pasada descontenta a muchos y contenta en exclusiva a los beneficiarios directos, o a los redactores del momento. La principal novedad de la LOU fue la pérdida de la denominada autonomía universitaria. En este artículo se trata dicho tema, aparte de otros apartados de la nueva Ley, los órganos de gestión, el Consejo Social, los planes de estudio o la investigación en la Universidad española. 


\section{PALABRAS CLAVE}

Universidad - LOU - Autonomía universitaria - Investigación

\section{ABSTRACT}

The past and present of the university makes many unhappy and exclusive content direct beneficiaries, or the authors of the time. The main novelty of the LOU was the loss of the so-called autonomy. This article treats that theme, besides other sections of the new law, the management bodies, the Social Council, plans for study or research in Spanish university.

\section{KEY WORDS}

University - LOU - University Autonomy - Research

\section{ÍNDICE}

1. Introducción

2. Los órganos de gestión

3. Docencia y planes de estudio

4. La investigación en la Universidad española

5. La selección del profesorado

6. Cómo debería ser 


\section{TEXTO:}

\section{Introducción}

Para mí, que realicé los estudios de Medicina y Cirugía en los años 60 y que he estado vinculado a diversas universidades españolas desde entonces, salvo los periodos que pasé en algunos centros extranjeros de investigación, escribir sobre esta institución de enseñanza y sobre las leyes que la rigen tiene un marcado carácter autobiográfico. Y de la mía y de otras biografías más o menos próximas se colige que existe un descontento, mantenido a lo largo de los años, cuando se habla de la institución. La Universidad presente y pasada descontenta a muchos y contenta en exclusiva a los beneficiarios directos, o a los redactores del momento. Por ejemplo, en la prensa diaria puede seguirse el desacuerdo de los gestores de la Ley Orgánica de Universidades (LOU) con la precedente Ley de Reforma Universitaria (LRU), y viceversa.

La protesta principal de los últimos Rectores LRU, y de otros estamentos sociales, contra la LOU se fundamentó en la pérdida de la denominada autonomía universitaria. Este es uno de esos grandes conceptos que llenan nuestra cartera mental de pagarés sin fondos, porque con la LRU todas las universidades españolas habían sido (es de esperar) autónomas, lo que en un previsible devenir evolutivo las podría haber hecho diferentes entre sí (cada una utilizando la autonomía para alcanzar un carácter peculiar), cosa que no ocurrió. ¿Se notaría si la Universidad de la ciudad X (gestores, profesores y licenciaturas incluidas) se instala de repente en la ciudad Y? La autonomía disfrutada por las universidades españolas durante el periodo LRU no las hizo diferentes, sino coparticipes de defectos estructurales y funcionales similares. ¿Cómo a ninguna universidad se le ocurrió, con el numerosísimo número de partícipes (Claustros, Juntas de Gobierno, Juntas de Centro, etc.) contratar a diez premios Nobel, o a otras tantas figuras excelsas de la 
ciencia o las letras, para mejorar su nivel académico? ¿Cómo todas al paso incurrieron, ¡cielos!, en la denostada endogamia? La recién llegada LOU, para no ser menos, promete más autonomía aún, lo que despierta en mí el previsible temor de que nos haga a todos más disconformes todavía. Prueba, tal vez, de la corta distancia que separa en la práctica a ambas leyes es que la mayoría de rectores LRU siguen al mando, R que R, con la malquerida LOU.

De hecho, tanto la LRU como la LOU conceden un alto grado de autonomía en la gestión de los fondos públicos que se asignan a cada institución, detraídos los gastos del personal funcionario, que no son mal pellizco. El Rector en la LOU sigue respondiendo de su actividad ante el Claustro, órgano colegiado multitudinario (de hasta 300 miembros), del que no sé si mi amigo, el Prof. Carlos Acuña, lo incluiría en su lista de órganos regidos por la "democracia de los pequeños números", esto es, susceptibles de ser manipulados por grupos de presión y por intereses torticeros.

El Consejo Social propuesto en la LOU es previsible que pinte tan poco como en la LRU, refugio que fue de figuras políticas colaterales y de poca acción real. A mi entender, el Rector de una Universidad pública debe dar cuentas de su gestión al Consejo Social, el cual debe ser un intermediario real entre la Universidad y los poderes públicos autonómicos, con especial incidencia en la financiación suficiente, y de fuentes variadas, de la institución, y con particular repercusión en el buen rumbo de la misma. Así, cada Universidad será representativa del entorno que ocupa, ligada a su desarrollo y promoción. Con la LRU y la LOU, la Universidad es más autárquica que autónoma; es decir, autogestionaria y poco interdependiente de su entorno económico y social. Por lo demás, la Universidad española se masificó a lo largo del siglo pasado, pero no se hizo diversa, ni mucho menos dispar.

\section{Los órganos de gestión}


El Rector LOU tiene más poder decisorio frente al Claustro, como órgano representativo de la comunidad universitaria, que con la LRU. No así los Decanos y Directores de Departamento, porque en los sucesivos borradores de la LOU pasaron de presidir meros "órganos de consulta y asesoramiento" a auténticos "órganos de gobierno". El matiz no es pequeño, porque gran parte de los problemas prácticos que acarreó la LRU (tal vez no deseados por sus redactores) provinieron del mal uso que se hizo de la gestión de los Departamentos, encargados de la docencia e investigación asignada a los mismos. ¡Tanta batalla parlamentaria y callejera para terminar en el mismo problema! Así, es previsible que equipos científicos, laboratorios, docencia reglada, etc. no se distribuyan con criterios de "docencia de calidad" e "investigación de excelencia" como prevé la LOU en su exposición de motivos, sino por reñidas votaciones donde el voto del despistado (¿podría incluso haber sino "tocado" antes por alguien?) decide la ubicación y uso del contador de centelleo adquirido mediante el proyecto de un grupo de investigación. No debe olvidarse que un artículo de ley no escrita, consecuencia de la LRU, fue que, pongamos por caso, un microscopio es propiedad y responsabilidad exclusiva del investigador principal del proyecto por el que fue concedido mientras su factura está sin pagar, pero pasa a ser propiedad inmediata de la Comunidad Autónoma, Universidad, Centro y Departamento (todos los interesados incluidos) tan pronto aquella se abona. El detalle pequeño es a veces el más perjudicial. Escasas veces se verá un profesor determinado teniendo que defender ante un iracundo Consejo de Departamento si su docencia atenta contra las leyes de la Creación o contra el concepto de Estado, pero muchas tendrá que enfrentarse con un baremo diseñado para "evitar" la contratación de un investigador de fuste, o con la malévola redacción del reglamento de acceso a la fotocopiadora los domingos por la tarde.

Un órgano colegiado novedoso, creado por la LOU, es la Junta Consultiva, formada por hasta cuarenta "profesores e investigadores - ¿por qué la conjunción que los separa?- de reconocido prestigio" de la Universidad. Mal asunto si a los profesores de 
reconocido prestigio se les destina al lugar de las consultas y no al del gobierno de la institución. Sabido es que este es el saldo final de un intento inicial de que el gobierno de la Universidad estuviese en manos de estos prestigiosos individuos. La LOU aprobada pone el gobierno universitario en manos de un Rector elegido por la comunidad universitaria "mediante elección directa y sufragio universal libre y secreto". El candidato a Rector ha de contar con medios económicos para hacer llegar su programa a tan numeroso censo de votantes potenciales, pero en ningún caso se le exige, ni a él ni a su equipo, que sean de "reconocido prestigio". Se espera, por lo visto, que se lo ganen con el ejercicio de sus funciones gestoras.

\section{Docencia y planes de estudio}

El legislador español no se fía nada-nada de sus huestes y por eso legisla con detalle minucioso, para que nadie encuentre lo que se encuentra siempre, esto es, los agujeros de lo legislado. La gestión universitaria adolece de este detallismo en leyes y su posterior desarrollo en decretos y reglamentos. ¿Podrán creer que mi anterior Facultad tenía una comisión encargada del control de las tapas del bar? Prueba de ese encorsetamiento es el diseño de los nuevos planes de estudio que sacudió a la Universidad española hace unos años y que todavía colea. Los planes de estudio iban a ser flexibles, adaptables a las necesidades del alumno, democráticos en su elaboración y no sé cuantas cosas más, pero terminaron determinados de manera masiva desde el Ministerio correspondiente, con multitud de cuñas docentes (léase asignaturas obligatorias, optativas, de libre elección, etc.) determinadas (jtambién aquí!) por la configuración de votos de las Juntas de Facultad y de los Consejos de Departamento correspondientes. ¡Tantos participantes para tan magro resultado! Además, salvo alguna honrosa excepción, ninguna Universidad hizo uso de su preciada autonomía para crear unos estudios originales, distintos, imaginativos, de calidad o, simplemente, divertidos. Y abundando en lo mismo, todavía se ataca a 
algún plan de estudios que yo conozco, porque es (ligeramente) distinto del resto de los aprobados en otras tantas Universidades del país.

Los estudios del Tercer Ciclo pudieron representar la salida al dilema, ya que eran susceptibles de mayor flexibilidad. Una nota a favor del Ministerio de Educación, Cultura y Deporte ha sido la financiación de Programas de Doctorado de Excelencia. Esta última se determina por la profundidad de los programas docentes propuestos, la calidad del profesorado seleccionado y la participación de alumnos de diversa procedencia. Una iniciativa de este calibre debería ser potenciada y no olvidada, aunque la LOU no la menciona explícitamente. De cualquier manera, los estudios de Doctorado fueron rápidamente engullidos por la trituradora burocrática de los equipos rectorales y donde hacía falta ayuda se puso norma, y donde hacía falta dinero se colocó un formulario, y para dar flexibilidad se instalaron algunos pilares de hormigón. En este caso particular, si la LOU saca adelante estos estudios, yo personalmente se lo agradeceré, porque es el espacio que queda para hacer "docencia de calidad" e "investigación de excelencia", como propugna la misma Ley.

Por último, las ayudas económicas individualizadas, que la LOU propone en sus artículos 55 y 69, para aquellos profesores de especial valía docente o investigadora (ver apartado siguiente), dependerán en su aplicación del propio Rectorado, de la Comunidad Autónoma correspondiente y, tal vez, del Gobierno central. Visto lo ocurrido con propuestas similares en la LRU y de sus borradores iniciales, estas ayudas desprenden un aromático olor a una bebida de uso común en el país, al alcance de todos.

\section{La investigación en la Universidad española}

Mi profesor de Lógica solía contar que él era catedrático de la Facultad de Filosofía y Letras, y hacia un ligero movimiento de vaivén con la mano derecha al pronunciar lo 
que sigue a la conjunción. El asunto no es baladí, sino que enfrenta uno de los grandes problemas de la Universidad de nuestro país. La LRU en su artículo primero afirmaba que la Universidad realiza la educación superior mediante "la docencia, el estudio y la investigación", aunque en la práctica, mientras que (casi) todos los profesores universitarios dan clases y estudian (algo al menos) para prepararlas, no más de un $20 \%$ de los mismos investigan (es decir, disponen de fondos públicos o privados para hacerlo). La LOU quiere tomar el problema por las pipetas y propone que el mismo servicio (educación superior) se llevará a cabo mediante "la investigación, la docencia y el estudio".

En la Universidad, el trabajo de investigación lo hace en realidad el Grupo de Investigación, entidad algo fluctuante, porque no tiene reconocimiento en la LOU (se menciona de pasada), ni lo tuvo en la LRU. No se define su constitución, colegiada o no, si se determinan las funciones de su responsable, ni las de sus miembros. La LOU tampoco determina las relaciones de los Grupos de Investigación (gestión de su financiación, espacios, uso de su instrumentación, etc.) con el Departamento del que, necesariamente, forman parte. El Grupo de Investigación como tal merecía un tratamiento más explícito en la LOU, de manera que quedase protegido por ese nuevo paraguas legal y no a la intemperie como estuvo durante el reinado de la LRU, fuente continua del malestar indicado al inicio de este texto. El único refugio coherente que la LRU ya ofrecía, y que la LOU mantiene, es la creación de Institutos de Investigación. El problema de los Institutos es que requieren un número considerable de profesores/investigadores, más un poder académico considerable, para que los Rectorados los concedan y para que las Comunidades Autónomas los aprueben y financien. Una Universidad modesta y de recursos limitados debería defender con todo ahínco que en su seno se desarrollen grupos de investigadores que dedican su tiempo a buscar respuestas a preguntas muy variadas mediante el método experimental por interés, gusto o afición. 
La investigación (como la docencia) es obligación de todo el profesorado universitario, pero los Rectorados vigilan estrictamente el cumplimiento de la segunda y apenas prestan atención a la primera, entre otros detalles porque no da votos. Así fue con la LRU y así lo será, previsiblemente, con la LOU, que se aplica al mismo profesorado anterior, con una notable ampliación de última hora. La virtud de los científicos modestos es la perseverancia venía a decir don Santiago Ramón y Cajal, pero hay que hacerles un hueco legal en una ley futura, ya que en la LOU no se les encontró, y triste es constatar que la perseverancia tiene un límite. Prueba fehaciente de lo que digo es la corta vida media del investigador universitario en nuestro país (suelen fenecer para la ciencia a una edad variable, que oscila entre los 30-50 años, según perseverancia y otros factores), si se compara con la del entorno europeo o norteamericano.

\section{La selección del profesorado}

Esta sección no merece ser escrita por obvia, ni leída por conocida, ni reelaborada -en forma de propuesta para el porvenir- por inútil. Baste recordar el porcentaje de endogamia de todos los centros universitarios del país (otra prueba más de su falta de identidad, de autonomía verdadera) y de la limitada capacidad de los equipos rectorales para controlar el proceso. La LRU dejó la tarea de definir las necesidades docentes, determinar los perfiles de las plazas a convocar y proponer nombres y apellidos de dos quintos de los profesores encargados de evaluar a los candidatos a los Consejos de Departamento. La Ley puso el marco y las medianías imperantes hicieron el resto. Ya decía nuestro querido Juan de Mairena que no se deben otorgar cargos públicos a las medianías, ya que su capacidad cognitiva es limitada, como lo es también su moralidad. Ahora que Medline se ha convertido en una suerte de espejo de Blancanieves sonroja ver los Currícula de tanto profesor funcionario con listado de publicaciones de tan breve recorrido. 
Aunque no tengo los números precisos, la Universidad española pasó en veinte años de 2.000 a 20.000 profesores numerarios, y en los albores de la novedosa LOU hizo un esfuerzo supremo para ponerse en los 45.000, con unos 5.000 más pendientes de pasar por el correspondiente concurso-oposición en los próximos meses. El nuevo sistema nacional de habilitación puede mejorar el proceso de selección (siempre maleable, con poco que los expertos se lo propongan), pero no puede generar muchos nuevos puestos de trabajo. A no ser que determinadas Universidades emprendan una auténtica marcha en pos de la calidad docente, que entre otras cosas supondría alcanzar el número mágico de un profesor por cada nueve alumnos.

\section{Cómo debería ser}

Entiendo que para hacer una buena Universidad hacen falta buenos profesores, alumnos bien seleccionados y dinero para financiar la empresa. El Rector puede ser nombrado o elegido de varias formas distintas, pero él y su equipo deben rendir cuentas ante un Consejo Social representativo del entorno social y económico del centro, porque el dinero es público en su mayor parte y lo aporta la sociedad, no el Claustro universitario. Para que la institución viva económicamente del prestigio de sus licenciaturas oficiales y de otras actividades docentes peculiares (programas propios, doctorados, maestrías) nada mejor que sea el alumnado quien cubra parte importante de los gastos, y que el Estado apoye de verdad (no como hasta ahora) el estudio de TODO alumno/a con capacidad demostrada. Los profesores serán seleccionados con cuidado exquisito por aquellas instituciones en las que el cargo y salario del equipo rectoral dependa de los resultados obtenidos, que se fundamentan en una mayor demanda por parte de alumnos de calidad (becados) y de investigadores y docentes en periodo de formación.

La Universidad ha de estar abierta a las ideas innovadoras. Es evidente que algunos planes de estudio han de ser reglados (Medicina, Ingeniería), pero también lo es que 
otros deber dejar margen a la iniciativa y a la imaginación (Biología, Filosofía). Podría haber estudios, así mismo, destinados a entender el Universo que nos rodea, a saber sin más. En los últimos 50 años, la Universidad ha sido cambiada por leyes emanadas del Gobierno/Parlamento siguiendo una evidente demanda social. La dirección de la flecha ha de cambiar y ser la Universidad la que envíe signos inequívocos (dolorosos a veces) de necesario reajuste, de transformación del entorno socio-económico. La Universidad no debe continuar como inmueble de semi-lujo y asilo de jóvenes, sino pasar valientemente a ser motor de la sociedad que la sostiene y a la que debe servir.

Parafraseando a Gil de Biedma, podría decir que la historia que yo puedo abarcar (por vivida) de la Universidad española ha sido la más triste de todas las historias universitarias, porque siempre acabó mal. Bien es verdad que otros no son tan pesimistas, y así Paul Valery sugiere que el conocimiento del pasado y del presente pueden servir para garantizar el futuro; esto es, que los que no conocen su historia están obligados a repetirla.

\section{Referencias}

BRICALL, Josep M. Universidad 2 mil. CRUE. Madrid. 2000.

Federación Nacional de Asociaciones de Catedráticos de Universidad, Informe para un debate. Madrid. 2001.

Ley Orgánica de Universidades, 121/000045. Boletín Oficial de las Cortes Generales, 26-12-2001.

Ley Orgánica de Reforma Universitaria, 11/1983. B.O.E., de 1-9-1983. 
MARCOVITCH, Jacques. La Universidad (im)posible. Cambridge University Press. Madrid. 2002.

ORTEGA Y GASSET, José. "Misión de la Universidad" en la Revista de Occidente. Alianza Editorial. Madrid (1930). 1997.

PECES-BARBA, Gregorio. “Elogio de la LRU” en Diario El País, pág. 15, 18-9-2002. SACRISTÁN, Manuel. “La Universidad y la división del trabajo" en la revista Realidad, vol. 21, 1971. 